\title{
African iron overload
}

INSERM

\section{Source}

INSERM. (1999). Orphanet: an online rare disease and orphan drug data base. African iron overload. ORPHA:139507

African iron overload is a rare disorder described in sub-Saharan African populations and is characterized by iron overload due to excess dietary iron intake and possibly genetic factors, leading to hepatic portal fibrosis and micronodular cirrhosis. 